\title{
Case report of high origin of radial, ulnar, and profunda brachii arteries, its clinical implications and review of the literature
}

\author{
Relato de caso de origem alta das artérias radial, ulnar e braquial \\ profunda, suas implicações clínicas e revisão de literatura
}

\author{
Sampath Madhyastha, ${ }^{1}$ Soubhagya R. Nayak, ${ }^{2}$ Ashwin Krishnamurthy, ${ }^{2}$ Sujatha D'Costa, ${ }^{2}$ \\ Asha Anu Jose, ${ }^{2}$ Kumar M.R. Bhat ${ }^{3}$
}

\begin{abstract}
Arterial variations in the arm are of potential clinical implications as it is a frequent site of injury and also involved in many surgical and invasive procedures. During a dissection of the right upper extremity, an abnormal high origin of the radial and ulnar arteries was found. The brachial artery had a very short segment without any branches, divided into the radial and ulnar arteries at the upper third of the arm. The course and branching pattern of these radial and ulnar arteries in the arm are discussed. It was also observed that the profunda brachii artery was represented by two separate branches arising from the posterior circumflex humeral artery. Accurate knowledge of these variation patterns is of considerable clinical importance in the conduct of reparative surgeries around the shoulder and fracture management of the humerus. These additional data of arterial anomalies to contemporary anatomical literature are of interest to clinicians, in particular vascular and plastic surgeons and radiologists.
\end{abstract}

Keywords: Brachial artery, radial artery, ulnar artery, arterial variations.

\section{Introduction}

The brachial artery, a continuation of the axillary artery, begins at the distal border of the tendon of teres major and ends about a centimeter distal to the elbow joint by dividing into the radial and ulnar arteries. The artery is wholly superficial, covered anteriorly by skin and fascia and crossed superficially by the median nerve from the lateral to the medial side. ${ }^{1}$ The brachial artery gives origin to the following branches: profunda brachii, nutrient, superior and inferior ulnar collateral, muscular, radial, and ulnar arteries. The profunda brachii artery, a large branch from the brachial artery, distal to the teres major, follows the radial nerve closely between the long and medial head of the

\section{Resumo}

As variações arteriais no braço têm potenciais implicações clínicas já que o braço é um sítio de lesões frequentes, além de estar envolvido em muitos procedimentos cirúrgicos e invasivos. Durante a dissecção da extremidade superior direita, uma origem alta anormal das artérias radial e ulnar foi encontrada. A artéria braquial apresentava um segmento muito curto sem quaisquer ramos, dividindo-se nas artérias radial e ulnar no terço superior do braço. O curso e o padrão de ramificação das artérias radial e ulnar no braço são discutidos. Também se observou que a artéria braquial profunda estava representada por dois ramos separados, surgindo da artéria umeral circunflexa posterior. O conhecimento preciso sobre esses padrões de variação é de considerável importância na realização de cirurgias reparadoras na região do ombro e no manejo de fraturas de úmero. Estes dados adicionais sobre as anomalias arteriais para a literatura anatômica contemporânea são de grande interesse para os médicos, especialmente para cirurgiões plásticos e vasculares e radiologistas.

Palavras-chave: Artéria braquial, artéria radial, artéria ulnar, variações arteriais.

triceps and then in the radial groove. The profunda brachii artery gives origin to two terminal branches called radial collateral and middle collateral arteries. ${ }^{1}$

According to Compendium of Human Anatomic Variation, ${ }^{2}$ major variations are present in about $25 \%$ of the subjects studied for the brachial artery. The variations in the form of high proximal division into terminal branches occur in the radial artery (15\%), ulnar artery (2\%), common interosseous artery, vas aberrans, and superficial median antebrachial vein. This high division may occur at any point in the normal course of the vessel, but it is more common in the middle third. The two vessels into which the

1. Associate professor, Department of Anatomy, Kasturba Medical College, Mangalore, India.

2. Department of Anatomy, Kasturba Medical College, Mangalore, India.

3. Department of Anatomy, Kasturba Medical College, Manipal, India.

No conflicts of interest declared concerning the publication of this article. Manuscript received Dec 11 2008, accepted for publication Sep 12009.

$J$ Vasc Bras. 2009;8(4):374-378.

Copyright (C) 2009 by Sociedade Brasileira de Angiologia e de Cirurgia Vascular 
brachial divides run parallel to each other to the bend of the elbow, in the usual position of the brachial artery. From this point, one branch follows the normal course of the radial artery through the forearm and the other one takes the normal course of the ulnar artery. This arrangement is considered a simple high division of the brachial artery. ${ }^{2}$ In the present case report, we focused on the anatomical topography of this arterial variation and discussed its morphological and clinical significance.

\section{Case report}

The variation was observed during a routine dissection of a female cadaver aged about 70 years in the dissection hall of the Department of Anatomy, Kasturba Medical College, Mangalore, India. The individual's history and cause of the death are unknown. The findings observed on the right upper extremity are described below.

- The brachial artery was divided at the upper third of the arm into radial and ulnar arteries, about $4 \mathrm{~cm}$ distal to the lower border of teres major muscle (Figures 1 and 2).

- The radial artery crossed superficially to the median nerve and then descended laterally to it.

- In the upper part of the arm, the ulnar artery descended medially to the median nerve, but lower down, the median nerve crossed the ulnar artery superficially from the lateral to the medial side.

- The radial and ulnar arteries descended parallel to each other in the arm, deep to the biceps brachii muscle,

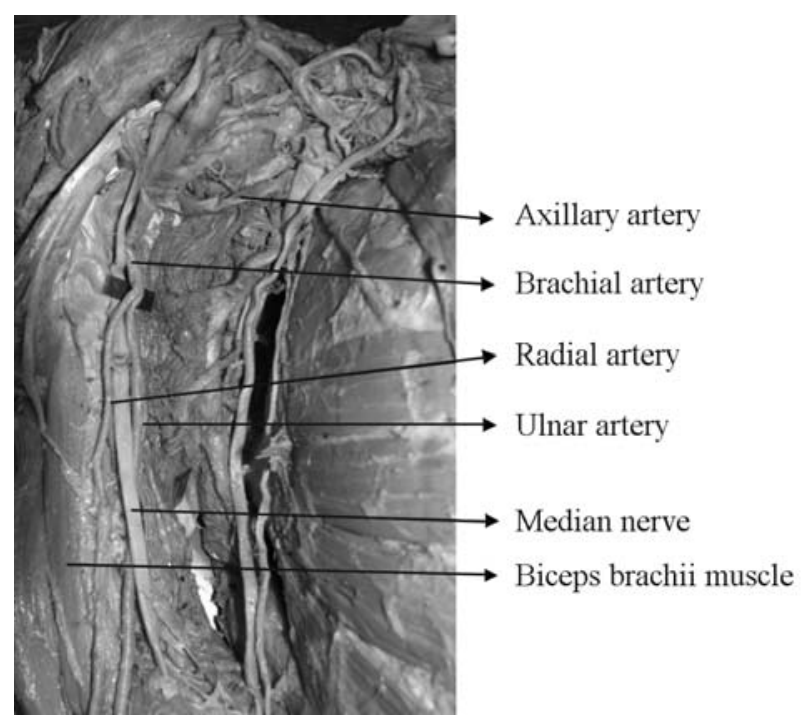

Figure 1 - Higher division of brachial artery into radial and ulnar arteries

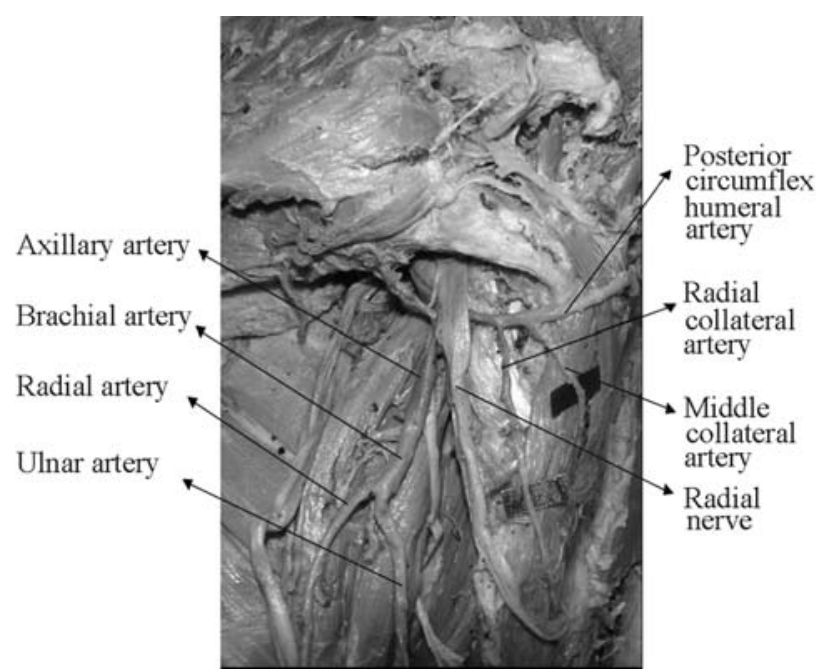

Figure 2 - Posterior circumflex humeral artery giving origin to radial and middle collateral arteries

and, in the cubital fossa, the radial artery passed through the apex of the fossa, while the ulnar artery passed deep to the deep head of the pronator teres muscle.

- The superior and inferior ulnar collateral arteries, muscular branches and nutrient artery to the humerus were arising from the ulnar artery in the arm. The branching of the radial and ulnar arteries was normal at the cubital fossa.

- It was also observed that the profunda brachii artery was represented by means of two separate branches (proximal and distal) arising from the posterior circumflex humeral artery (Figure 2).

- The proximal branch aroused from the posterior circumflex humeral artery and followed the radial nerve in the spiral groove and was considered as the radial collateral artery, which participated in the anastomosis in front of the lateral epicondyle.

- The distal branch arising from the posterior circumflex humeral artery descended lateral to the radial nerve and gave origin to the middle collateral artery, which participated in the anastomosis behind the lateral epicondyle.

\section{Discussion}

Variations in the branching pattern of the arteries of the upper limbs have clinical and surgical significance. ${ }^{3,4}$ A report presented by Celik et al. ${ }^{5}$ shows early division of the brachial artery into the radial and ulnar arteries after giving origin to the profunda brachii artery. In the present 
case, the profunda brachii artery was represented by two separate branches arising from the posterior circumflex humeral artery. Origin of the profunda brachii artery either from the anterior or posterior circumflex humeral artery was mentioned in the Compendium of Human Anatomic Variation, ${ }^{2}$ but its representation by two separate arteries is a rare variation. In the present case, we named these two arteries as radial collateral and middle collateral arteries due to their normal mode of termination.

A case report by Aharinejad et al. ${ }^{6}$ was almost similar to our present findings, except that the radial artery was located medial to the median nerve (in the present case it was on the lateral side) and the ulnar artery emerged immediately posteriorly to the brachial artery and ran laterally crossing ventral to the median nerve (in the present case, the radial artery crossed superficially to the median nerve immediately after its origin). A high origin radial artery occurs in $14.27 \%$ of the individuals $(15 \%$ according to Anson, ${ }^{7} 7.7 \%$ according to DeGaris \& Swartley, ${ }^{8}$ and 3\% according to Miller ${ }^{9}$ ), and it may arise as high as the axillary artery, but most commonly it arises from the proximal third of the arm. ${ }^{10,11}$

High origin of the radial artery is not uncommon. In a retrospective review by Celik et al. ${ }^{12}$ including 81 upper extremity arteriograms, high origin of the radial artery from the brachial artery was the most frequent variation, found in $87.5 \%$ of all variations. A similar percentage of high origin of the radial artery was also reported by Uglietta $\&$ Kadir. ${ }^{13}$ There are many such reports on high origin of the radial artery. ${ }^{14,15}$ In the present case, the radial artery crossed superficially to the median nerve and then descended laterally to it. While descending in the arm, the radial artery did not give origin to any branches. Recognition of the high origin of the radial artery in the arm as reported in the present case is crucial for clinicians. A 36-year-old Japanese woman undergoing chronic hemodialysis presented with a pseudoaneurysm from the high origin of the radial artery in the arm. ${ }^{16}$ The transradial approach for percutaneous coronary procedures has the advantage of reducing access site complications but it is associated with specific technical challenges in comparison with the transfemoral approach. Transradial procedure failures can sometimes be due to variation in the radial artery anatomy. ${ }^{17}$ This has implications for clinical practice and suggests a need for imaging of the radial artery before such procedure.

It is not uncommon to find the high origin of the ulnar artery. High origin of the ulnar artery from the brachial artery ${ }^{6,18}$ and also from the axillary artery ${ }^{19,20}$ has been reported. Kadanoff \& Balkansky ${ }^{21}$ described a high division of the axillary artery into a deep and superficial brachial artery. In one case, the ulnar artery branched from the deep artery, in the other case, it branched from the superficial brachial artery. In both cases, the ulnar artery was originated proximally to the cubital fossa and had a normal course toward the superficial palmar arch. However, in the present case, a "superficial brachial artery" was missing and the origin of the ulnar artery was by far higher than that described by these authors. A case of high origin of a superficial ulnar artery dorsally from the brachial artery was described by Fuss. ${ }^{22}$ Considering this terminology and with respect to the topography of the arterial variation, we did not use the term superficial brachial artery. Nevertheless, with regard to the ulnar artery descending in the arm in the present case, it is debatable whether it is to be named brachial artery and whether its further course in the forearm is to be named ulnar artery.

We also found a very rare case reported by Ciervo et al. ${ }^{23}$ claiming absence of the brachial artery. The brachial artery was absent from its origin but reconstituted as a normal-appearing vessel $3 \mathrm{~cm}$ above the antecubital fossa. The profunda brachii artery and the superior and inferior ulnar collateral arteries were also absent in this patient. The axillary artery served as the main collateral for the forearm.

Variation in the branching pattern of the brachial artery is of significance in cardiac catheterization for angioplasty, pedicle flaps, or arterial grafting. Any abnormal positions or divisions of the brachial artery should be identified before surgery. But a full work up by CT-angiography for every single patient presenting to the emergency department is neither feasible, nor cost-effective. Hence we urge physicians to be aware of this possibility before initiating the procedure.

High bifurcation of the brachial artery presenting with acute ischemia secondary to an embolic event was reported by Cherukupalli et al. ${ }^{24}$ This anomaly was identified, and the ischemia was successfully resolved with embolectomy. 
The review of the profunda brachii artery states that this artery can be represented by two or three branches (type 1a and 1b) but has a normal origin from the brachial artery. In our present case, the profunda brachii artery was represented by two branches arising from the posterior circumflex humeral artery. This high origin of the profunda brachii artery is at a vulnerable site in downward dislocation of the shoulder joint. Though the percentages of arterial lesions are low in upper extremity dislocation, ${ }^{25}$ Bravman et al. ${ }^{26}$ emphasize its significance as a "diagnostic challenge" even in minor trauma. They present a case of anterior dislocation of the shoulder resulting in avulsion injury to the branches of the circumflex humeral artery with expanding hematoma in the axilla. Hence, a high level of suspicion, in conjunction with knowledge of sensitive and specific clinical signs is paramount for an accurate and timely diagnosis. High origin of the profunda brachii artery may be beneficial for collateral circulation connecting the distal part of the axillary artery with branches of the radial and ulnar arteries at anastomosis around the elbow.

Finally, any arterial variation can have both morphological and clinical significance. Cardiologists, radiologists, or vascular surgeons involved in the procedure should be attentive to these possibilities of anatomical alteration and require, in case of doubt, a color Doppler ultrasound of the limb. The case reported here may be of interest to angiologists and radiologists, as well as vascular surgeons.

\section{References}

1. Williams PL. Gray's anatomy. 38th ed. Philadelphia: Elsevier Churchill Livingstone; 1995.

2. Bergman RA, Thompson SA, Afifi AK, Saadeh FA. Compendium of human anatomic variation. Baltimore: Urban \& Schwarzenberg; 1988.

3. Jurjus A, Sfeir R, Bezirdjian R. Unusual variation of the arterial pattern of the human upper limb. Anat Rec. 1986;215:82-3.

4. Tountas $\mathrm{CH}$, Bergman RA. Anatomic variations of the upper extremity. New York: Elsevier Churchill Livingstone; 1993.

5. Celik HH, Sargon MF, Konan A, Kural E. High brachial artery bifurcation: a report of 2 cases. Bull Assoc Anat (Nancy). 1996;80:13-4.

6. Aharinejad S, Nourani F, Hollensteiner H. Rare case of high origin of the ulnar artery from the brachial artery. Clin Anat. 1997; 10:253-8.

7. Anson BJ. Morris' human anatomy. In: Thomas M, editor. The cardiovascular system-arteries \& veins. New York: McGraw Hill; 1966.
8. De Garis CF, Swartley WB. The axillary artery in white and Negro stocks. Am J Anat. 1928:41;353-97.

9. Miller RA. Observations upon the arrangement of axillary artery \& brachial plexus. Am J Anat. 1939;64:143-63.

10. McCormack LJ, Caudlwell EW, Anson BJ. Brachial and antebrachial arterial patterns; a study of 750 extremities. Surg Gynecol Obstet. 1953;96:43-54.

11. Golan J, Kaus M, Szwarc P. High origin of the ulnar and radial arteries in humans. Folia Morphol (Warsz). 1994;53:3748.

12. Celik HH, Görmüs G, Aldur MM, Ozçelik M. Origin of the radial and ulnar arteries: variations in 81 arteriograms. Morphologie. 2001;85:25-7.

13. Uglietta JP, Kadir S. Arteriographic study of variant arterial anatomy of the upper extremities. Cardiovasc Intervent Radiol. 1989;12:145-8.

14. Içten N, Süllü Y, Tuncer I. Variant high-origin radial artery: a bilateral case. Surg Radiol Anat. 1996;18:63-6.

15. Gonzalez-Compta X. Origin of the radial artery from the axillary artery and associated hand vascular anomalies. J Hand Surg Am. 1991;16:293-6.

16. Noguchi M, Hazama S, Tsukasaki S, Eishi K. Iatrogenic pseudoaneurysm in a hemodialysis patient: the hidden hazard of a high radial artery origin. Heart Vessels. 2004;19:98-100.

17. Lo TS, Nolan J, Fountzopoulos E, et al. Radial artery anomaly and its influence on transradial coronary procedural outcome. Heart. 2009;95:410-5.

18. Tohno S, Tohno Y, Yamaoka J, Yamaguchi S, Yamaguchi T, Yamane T. Anomaly of the ulnar artery arising from the brachial artery. Kaibogaku Zasshi. 1995;70:31-4.

19. Jacquemin G, Lemaire V, Medot M, Fissette J. Bilateral case of superficial ulnar artery originating from axillary artery. Surg Radiol Anat. 2001;23:139-43.

20. Nakatani T, Tanaka S, Mizukami S, Shiraishi Y, Nakamura $\mathrm{T}$. The superficial ulnar artery originating from the axillary artery. Ann Anat. 1996;178:277-9.

21. Kadanoff D, Balkansky G. [2 cases with rare variations of arteries of the upper extremities.] Anat Anz. 1966;118:289-96.

22. Fuss FK. [A superficial ulnar artery with high origin and atypical location.] Gegenbaurs Morphol Jahrb. 1988;134:215-20.

23. Ciervo A, Kahn M, Pangilinan AJ, Dardik H. Absence of the brachial artery: report of a rare human variation and review of upper extremity arterial anomalies. J Vasc Surg. 2001;33:191-4.

24. Cherukupalli C, Dwivedi A, Dayal R. High bifurcation of brachial artery with acute arterial insufficiency: a case report. Vasc Endovascular Surg. 2007;41:572-4.

25. Sparks SR, De La Rosa J, Bergan JJ, Hoyt DB, Owens EL. Arterial injury in uncomplicated upper extremity dislocations. Ann Vasc Surg. 2000;14:110-3.

26. Bravman JT, Ipaktchi K, Biffl WL, Stahel PF. Vascular injuries after minor blunt upper extremity trauma: pitfalls in the recognition and diagnosis of potential "near miss" injuries. Scand J Trauma Resusc Emerg Med. 2008;16:16. 
Correspondence:

Dr. Sampath Madhyastha

Associate Professor, Department of Anatomy

Kasturba Medical College

575001 - Mangalore, India

Tel.: +91 (824) 242.3452, 242.3654, 242.2271

Fax: +91 (824) 242.8183

E-mail: madhyast1971@gmail.com

\section{Author contributions}

Conception and design: SM

Analysis and interpretation: AK, SRN
Data collection: AAJ

Writing the article: SM

Critical revision of the article: KS

Final approval of the article*: SM, SRN, AK, SDC, AAJ, KMRB

Statistical analysis: N/A

Overall responsibility: SM

Obtained funding: N/A

* All authors have read and approved the final version of the article submitted to J Vasc Bras. 